\title{
Desenvolvimento da disciplina de Cálculo Numérico tendo um modelo em Ecologia como eixo norteador
}

\section{Resumo}

Neste artigo mostramos parte do desenvolvimento da disciplina de Cálculo Numérico tendo como eixo norteador um problema em ecologia matemática. É introduzido ao aluno um problema de valor inicial com uma equação diferencial tendo significado biológico, significado que é absorvido conforme o aluno avança nas técnicas do curso. Com o avanço das técnicas, o aluno obtém resultados numéricos e os apresenta em formato de texto científico. A parte apresentada cobre os métodos numéricos para resolução de problemas de valores iniciais começando em Euler-explícito e Euler-implicíto, onde, neste último, aplicamos as técnicas para obter zeros de função. Numa etapa final refinamos o problema de valor inicial e fazemos novos experimentos numéricos com auxílio de métodos numéricos mais eficientes, como o clássico método de Runge-Kutta de quarta ordem.

Palavras-chave: Cálculo numérico, Euler-implícito, Euler-explícito, Métodos de Runge-Kutta, Ecologia matemática, Modelos populacionais.

\begin{abstract}
In this article, we show part of the development of the Numerical Calculus course, with a problem in mathematical ecology as its guiding axis. An initial value problem with a differential equation with biological meaning is introduced to the student, that meaning is absorbed according to the student who is learning about course techniques. With the advancement of techniques, the student obtains numerical results and presents them in a scientific text format. The part presented covers the numerical methods for solving initial value problems starting with Euler-explicit and Eulerimplicit, where in the latter method we apply the techniques to obtain function zeros. In a final step, we refine the initial value problem and make new numerical experiments with the aid of more efficient numerical methods, such as the classic fourth-order Runge-Kutta method.
\end{abstract}

keywords: Numerical Calculus, Euler-explicit, Euler-implicit, Runge-Kutta methods, Ecology, population models.

\section{Introdução}

Este trabalho tem por objetivo apresentar o desenvolvimento do curso de Cálculo Numérico tendo um problema de valor inicial com uma equação diferencial ordinária (PVI) como o eixo norteador. Essa ideia faz com que as resoluções numéricas desses problemas sejam o principal foco do curso, 
onde há um espaço importante para o aluno apresentar os resultados que vem obtendo e treinar sua escrita científica. O curso foi ministrado por um dos autores, e o PVI sugerido é bastante simples e visível, mas teve o cuidado de, durante sua construção, as soluções dos problemas intermediários terem soluções exatas, onde conseguimos exibir de forma simples o que é a solução numérica de um PVI, uma vez que conseguimos comparar com a solução exata do problema. Assim, para o estudante, fica o objetivo de escrever um texto descontraído/agradável conforme o professor avança com o conteúdo em sala de aula. Acreditamos que tal abordagem seja interessante antes ou depois de um primeiro curso de equações diferenciais ordinárias, já que as modelagens são bastante simples e as análises qualitativas do problema ficam bastante evidentes. São os exemplos abordados meramente ilustrativos, sem qualquer compromisso com a realidade, levando em consideração que Cálculo Numérico é o primeiro curso nesse ambiente.

Nota-se, através de pesquisas como as de Soares e Sauer em [13], que há um certo padrão a respeito da apresentação de conteúdos, enfoques, bibliografia e técnicas de ensino nos cursos de Cálculo Numérico de algumas universidades brasileiras, sendo o programa clássico dessa disciplina resumido a: erros computacionais, raízes de funções, sistemas lineares, interpolação, integrais, ajuste de curvas e equações diferenciais, levando em consideração que esses autores notaram que em alguns planos de ensino não constam equações diferenciais. Além disso, a metodologia utilizada nos processos de ensino-aprendizagem é composta de explicações teóricas, seguidas de uma bateria de exercícios a serem resolvidos com o uso de calculadoras e/ou de softwares computacionais, além de trabalhos que envolvem a produção de programas com as técnicas apresentadas. Dessa forma, o ensino dos conteúdos a serem apresentados durante a disciplina pode tornar-se desestimulante e sem sentido para os aprendizes, visto que esses buscam um significado das ferramentas a serem aprendidas no curso em sua área de formação. Assim, nos propomos a trabalhar com um texto em ecologia matemática de dinâmica populacional, onde é estudado um modelo de crescimento populacional logístico com um termo de predação, que pode sofrer acentuações (como uma epidemia, guerra, migração etc.) ao longo do tempo. O texto proposto é clássico na literatura, por exemplo no primeiro capítulo de [11], e a proposta é basicamente a construção do texto com as ferramentas que vamos absorvendo ao longo do semestre. No decorrer do curso exibimos experimentos numéricos a fim de entender a dinâmica estudada.

Além disso, vale a pena comentar que, apesar dos métodos de Euler implícito ou explícito não serem de uso comum, foram utilizados, pois acreditamos que são extremamente didáticos para o entendimento do que é uma solução numérica para um problema de valor inicial com uma Equação Diferencial Ordinária. Após a apresentação desses métodos, a aprendizagem dos alunos em relação aos métodos mais sofisticados pode ser facilitada. Foi explorada também neste texto uma porção considerável na disciplina de Cálculo Numérico, a saber, os zeros de funções e os métodos de Runge-Kutta. Fica claro que métodos de interpolação ou ajustes de curva caberiam na discussão, mas limitamos esse trabalho apenas às soluções numéricas dos PVIs. No desenvolver do trabalho, escolhemos utilizar os métodos da bissecção e Newton-Raphson para aproximação de zeros de funções e método de Runge-Kutta de quarta ordem por ser o de uso mais comum.

Uma ferramenta tecnológica que nos auxiliou no desenvolvimento do curso foi o software Matlab, porém, outros softwares clássicos de programação podem ser utilizados a fim atingir a metodologia aplicada. Por fim, foi importante perceber que o interesse dos estudantes por avançar na disciplina teve uma avaliação satisfatória, visto que parte substancial desse artigo é o trabalho de uma das alunas do curso, o qual aqui o refinamos para dar um enfoque didático. Como afirmam Barbosa e Canalli em [3], acreditamos que as ações associadas no conjunto composto por alunos e professor têm por objetivo a estimulação para assimilação de conteúdos e técnicas facilmente aplicáveis aos 
aprendizes em diversas situações de maneira criativa e consciente.

A seguir, apresentaremos o desenvolvimento do modelo composto e os momentos em que as técnicas de Cálculo Numérico foram sendo apresentadas e trabalhadas.

\section{Apresentação do problema}

A Ecologia é o estudo científico da distribuição e abundância dos seres vivos e das interações que determinam a sua distribuição. As interações podem ser entre seres vivos e/ou com o meio ambiente. Ciência ampla e complexa, a Ecologia preocupa-se com o entendimento do funcionamento de toda a natureza. Um exemplo disso é a Ecologia de populações, onde modelos matemáticos realistas e úteis na biologia populacional são um forte objeto de estudos, uma vez que ajudam a entender os processos dinâmicos envolvidos e também a fazer previsões práticas. Talvez o mais comum no dia a dia sejam modelos com população humana, porém também é comum lidar nesses modelos com população de uma espécie ameaçada de extinção, crescimento bacteriano ou viral, entre outras.

Modelos de crescimento populacional são clássicos na literatura e são introduzidos desde os primeiros cursos de Cálculo. Esses modelos também costumam ser úteis e eficientes para descrever as sequências pelas quais as sociedades são transformadas. Denotamos por $\mathrm{N}(\mathrm{t})$ a densidade de uma certa população no instante de tempo t e consideramos que essa segue um crescimento logístico, seguindo [11] (Cap. 1, pp1-43, e ex. 4), dada por

$$
\left\{\begin{array}{l}
\frac{\mathrm{dN}}{\mathrm{dt}}=\mathrm{rN}\left(1-\frac{\mathrm{N}}{\mathrm{K}}\right) \\
\mathrm{N}(0)=\mathrm{n}_{0},
\end{array}\right.
$$

onde $\mathrm{r}$ representa um coeficiente de crescimento, $\mathrm{K}$ é entendido como a capacidade de carga do ambiente e $\mathrm{n}_{0}$ é a população inicial. Essa população pode passar pelo que chamaremos de efeitos de predação - por exemplo, se considerarmos a população humana, essa pode enfrentar períodos de guerras ou pandemias, ou também efeitos de imigração/emigração, tendo consequência direta na sua taxa de crescimento. Nessa ideia, completamos o PVI (1) para

$$
\left\{\begin{array}{l}
\frac{\mathrm{dN}}{\mathrm{dt}}=\mathrm{rN}\left(1-\frac{\mathrm{N}}{\mathrm{K}}\right)-\mathrm{P}(\mathrm{N}) \mathrm{F}(\mathrm{t}) \\
\mathrm{N}(0)=\mathrm{n}_{0},
\end{array}\right.
$$

onde $\mathrm{P}$ representa uma taxa de predação (que depende da população $\mathrm{N}$ ), $\mathrm{F}(\mathrm{t}$ ) é dada e representa se há ou não a presença do efeito predador. O PVI (2) diz que a população N cresce segundo um crescimento logístico e tem seu crescimento afetado quando há a presença do termo de predação $\mathrm{P}(\mathrm{N}) \mathrm{F}(\mathrm{t})$. Na literatura é comum $\mathrm{F} \equiv 1$, e algumas escolhas para $\mathrm{P}$ clássicas são

$$
\mathrm{P}(\mathrm{N})=\mathrm{P}_{0}\left(1-\mathrm{e}^{-\frac{\mathrm{N}^{2}}{\mathrm{~A}}}\right), \quad \mathrm{P}(\mathrm{N})=\frac{\mathrm{P}_{0} \mathrm{~N}^{2}}{\mathrm{~A}^{2}+\mathrm{N}^{2}},
$$

onde os parâmetros $\mathrm{A}$ e $\mathrm{P}_{0}$ são constantes positivas. Sendo assim, espera-se desse trabalho um estudo construtivo via métodos numéricos básicos das soluções numéricas e das construções dos PVIs

$$
\left\{\begin{array}{l}
\frac{\mathrm{dN}}{\mathrm{dt}}=\mathrm{rN}\left(1-\frac{\mathrm{N}}{\mathrm{K}}\right)-\mathrm{P}\left(1-\mathrm{e}^{-\frac{\mathrm{N}^{2}}{\mathrm{~A}}}\right) \mathrm{F}(\mathrm{t}) \\
\mathrm{N}(0)=\mathrm{n}_{0},
\end{array}\right.
$$


$\mathrm{e}$

$$
\left\{\begin{array}{l}
\frac{\mathrm{dN}}{\mathrm{dt}}=\mathrm{rN}\left(1-\frac{\mathrm{N}}{\mathrm{K}}\right)-\frac{\mathrm{P}_{0} \mathrm{~N}^{2} \mathrm{~F}(\mathrm{t})}{\mathrm{A}^{2}+\mathrm{N}^{2}} \\
\mathrm{~N}(0)=\mathrm{n}_{0} .
\end{array}\right.
$$

A proposta é estudarmos numericamente o desenvolvimento histórico (1), (3) e (4) de acordo com o desenvolvimento cronológico da disciplina de Cálculo Numérico, onde começaremos com os métodos mais simples para os casos iniciais e utilizaremos métodos mais sofisticados a fim de obter a solução para escolhas de F sendo constante (ou aproximadamente constante) na maior parte e ter certos picos de crescimento. Exemplos clássicos de funções com esse comportamento são as gaussianas $\mathrm{F}(\mathrm{t})=1+\mathrm{ce}^{-\frac{\left(\mathrm{t}-\mathrm{t}_{0}\right)^{2}}{\mathrm{~d}}}$, com parâmetros $\mathrm{c} \in \mathbb{R}$ e d $>0$ que podem ter significados absorvidos observando alguns exemplos nas figuras 1 e 2 .

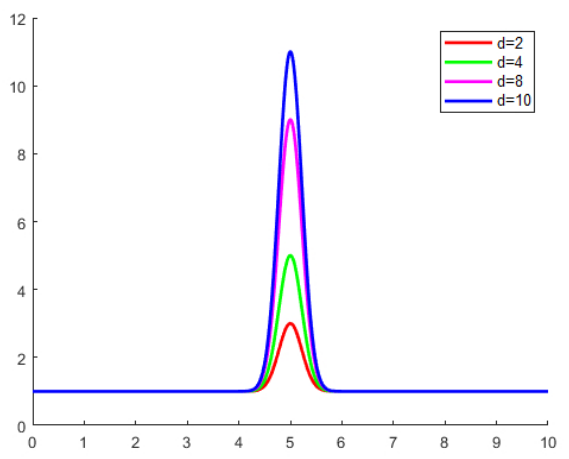

Figura 1: Propostas para F, onde consideramos $\mathrm{F}(\mathrm{t})=1+\mathrm{ce}^{-\frac{\left(\mathrm{t}-\mathrm{t}_{0}\right)^{2}}{\mathrm{~d}}} \operatorname{com} \mathrm{c}=0.1, \mathrm{x}_{0}=5$ e d como na figura.

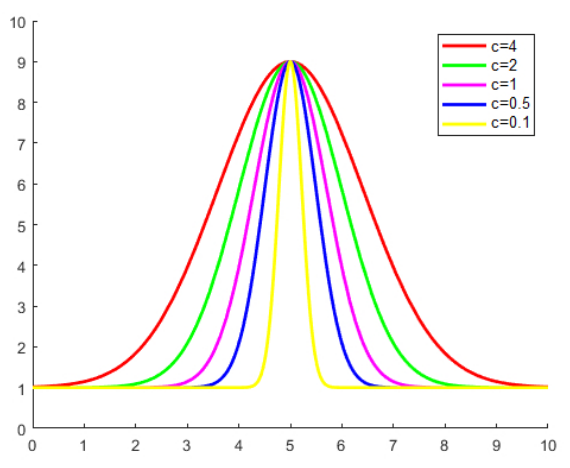

Figura 2: Propostas para F, onde consideramos $\mathrm{F}(\mathrm{t})=1+\mathrm{ce}^{-\frac{\left(\mathrm{t}-\mathrm{t}_{0}\right)^{2}}{\mathrm{~d}}} \operatorname{com} \mathrm{d}=8, \mathrm{x}_{0}=5$ e c como na figura.

Como exibido nessas figuras, o parâmetro c representa a intensidade adicional que o termo de predação apresentará, e d podemos entender como o tempo em que esse efeito acentuado ocorre.

\section{Desenvolvimento da proposta}

Representamos por N(t) a população da espécie no tempo t, então temos a relação

$$
\text { Variação de } \mathrm{N}=\text { Nascimentos - Mortes + Migração }
$$

que é uma equação de conservação para a população. A forma dos termos do lado direito de (5) requer modelar a situação com a qual estamos preocupados. O modelo mais simples nesse cenário não tem migração e é razoável supor que os termos de nascimento e morte são proporcionais à população $\mathrm{N}$, ou seja,

$$
\left\{\begin{array}{l}
\frac{d}{d t} N=b N-d N=n_{0}, \\
N(0)=N(t)=n_{0} e^{(b-d) t}=\text { solução exata, }
\end{array}\right.
$$

onde b e d são constantes positivas que representam a taxa de nascimento e morte da população, respectivamente, e a população inicial $\mathrm{N}(0)=\mathrm{n}_{0}$ que representa o número de indivíduos no instante 
inicial. Assim, se b > d, a população cresce exponencialmente, enquanto decresce exponencialmente se $b<d$.

Aproximar numericamente a solução de um problema de valor inicial pode ser entendido, basicamente, por obter uma quantidade de pontos $\left(\mathrm{t}_{1}, \mathrm{y}_{1}\right), \ldots,\left(\mathrm{t}_{\mathrm{n}}, \mathrm{y}_{\mathrm{n}}\right)$ de modo que a curva formada ao ligar pontos $\left(t_{i}, y_{i}\right)$ a $\left(t_{i+1}, y_{i+1}\right), i=1, \cdots, n-1$, via alguma interpolação (por exemplo, um segmento de reta), ganhe alguma suavidade.

Os métodos mais simples para ilustrar são os métodos de Euler-explícito (EE) e Euler-implícito (EI), que são oriundos, respectivamente, das seguintes discretizações:

$$
\mathrm{N}^{\prime}(\mathrm{t}) \approx \frac{\mathrm{N}(\mathrm{t}+\mathrm{h})-\mathrm{N}(\mathrm{t})}{\mathrm{h}} \quad \text { e } \quad \mathrm{N}^{\prime}(\mathrm{t}) \approx \frac{\mathrm{N}(\mathrm{t})-\mathrm{N}(\mathrm{t}-\mathrm{h})}{\mathrm{h}} .
$$

Apesar de serem raramente usados, são muito eficientes para ilustrar a ideia. A fim de aproximar numericamente a solução de (6) no intervalo $\left[0, \mathrm{~T}_{\text {final }}\right]$, onde $\mathrm{T}_{\text {final }}>0$ é um valor a ser escolhido, consideramos uma grade de tempos $\left\{t_{1}, t_{2} \cdots, t_{n}\right\}$, onde $t_{1}=0, t_{i+1}=t_{i}+h$ para $i=1, \cdots, n-1$, com $t_{n}=T_{\text {final }}$. Assim, $n$ e $h$ são relacionados por $h=T_{\text {final }} / n$. Denotamos, em ambos os casos, $\mathrm{N}_{\mathrm{i}}=\mathrm{N}\left(\mathrm{t}_{\mathrm{i}}\right)$. Também, $\mathrm{a}=\mathrm{b}-\mathrm{d}$. Com essa notação, podemos fazer a leitura das discretizações de (7) da seguinte forma:

Euler-explícito: $\quad \mathrm{N}^{\prime}(\mathrm{t}) \approx \frac{\mathrm{N}(\mathrm{t}+\mathrm{h})-\mathrm{N}(\mathrm{t})}{\mathrm{h}}=\frac{\mathrm{N} \text { avaliado um passo a frente }-\mathrm{N} \text { atual }}{\mathrm{h}}$

e

Euler-implícito: $\quad \mathrm{N}^{\prime}(\mathrm{t}) \approx \frac{\mathrm{N}(\mathrm{t})-\mathrm{N}(\mathrm{t}-\mathrm{h})}{\mathrm{h}}=\frac{\mathrm{N} \text { atual }-\mathrm{N} \text { avaliado um passo atrás }}{\mathrm{h}}$

A aplicação do método de Euler explícito resulta

$$
\frac{d}{d t} N=a N \Rightarrow \frac{N_{i+1}-N_{i}}{h}=a N_{i} \Rightarrow\left\{\begin{array}{l}
N_{i+1}=N_{i}+h a N_{i}, \quad i=1, \cdots, n-1 \\
N_{1}=n_{0} .
\end{array}\right.
$$

Para Euler-implícito, temos

$$
\frac{d}{d t} N=a N \Rightarrow \frac{N_{i+1}-N_{i}}{h}=a N_{i+1} \Rightarrow\left\{\begin{array}{l}
N_{i+1}=\frac{N_{i}}{1-a h}, \quad i=1, \cdots, n-1 \\
N_{1}=n_{0},
\end{array}\right.
$$

A nomenclatura explícito-implícito pode ser entendida preliminarmente da seguinte forma: para obtermos $\mathrm{N}_{\mathrm{i}+1}$ conhecendo $\mathrm{N}_{\mathrm{i}}$ via (EE) basta efetuar a operação descrita no algoritmo, já para obtermos $\mathrm{N}_{\mathrm{i}+1}$ conhecendo $\mathrm{N}_{\mathrm{i}}$ via (EI) precisamos fazer uma manipulação adicional, que nesse exemplo ultras-simplificado ainda pode não estar clara, que é calcular o zero de uma função. Desenvolveremos isso mais à frente; por ora, para fixar a ideia, consideremos para o PVI os dados

$$
\mathrm{n}_{0}=1 \quad \mathrm{a}=0.45, \quad \mathrm{~T}_{\text {final }}=4, \quad \text { e } \mathrm{h}=0.5
$$

isto é, aproximaremos numericamente a solução de

$$
\left\{\begin{array}{l}
\frac{\mathrm{d}}{\mathrm{dt}} \mathrm{N}=0.45 \mathrm{~N} \\
\mathrm{~N}(0)=1
\end{array} \quad \Rightarrow \quad \mathrm{N}(\mathrm{t})=\mathrm{e}^{0.45 \mathrm{t}}=\right.\text { solução exata. }
$$


Aproximaremos a solução em [0,4] com $\mathrm{h}=1$. Com algoritmos apresentados em (EE) e (EI) obtemos o resultado apresentado na Tabela 1. Com esse resultado, em Matlab, implementamos como na Figura 3.

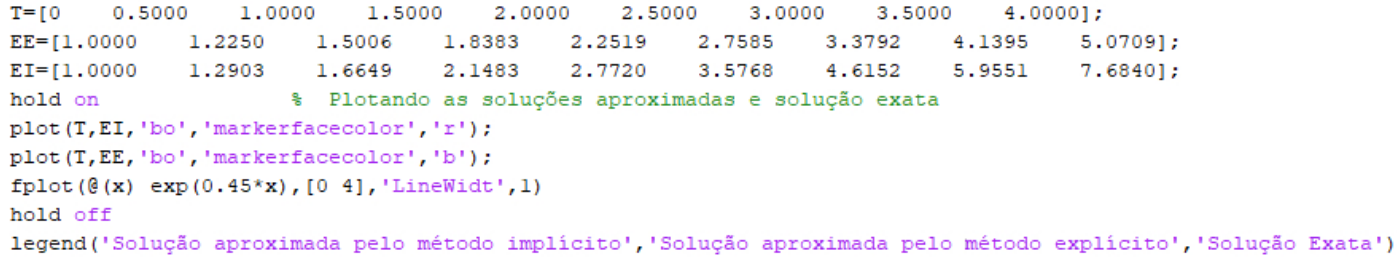

Figura 3: Plotando em Matlab o resultado obtido na Tabela 1

\begin{tabular}{|c|c|c|}
\hline $\mathbf{t}$ & $\mathbf{E E}$ & $\mathbf{E I}$ \\
\hline \hline 0 & 1.0000 & 1.0000 \\
\hline 0.5 & 1.2250 & 1.2903 \\
\hline 1.0 & 1.5006 & 1.6649 \\
\hline 1.5 & 1.8383 & 2.1483 \\
\hline 2.0 & 2.2519 & 2.7720 \\
\hline 2.5 & 2.7585 & 3.5768 \\
\hline 3.0 & 3.3792 & 4.6152 \\
\hline 3.5 & 4.1395 & 5.9551 \\
\hline 4.0 & 5.0709 & 7.6840 \\
\hline
\end{tabular}

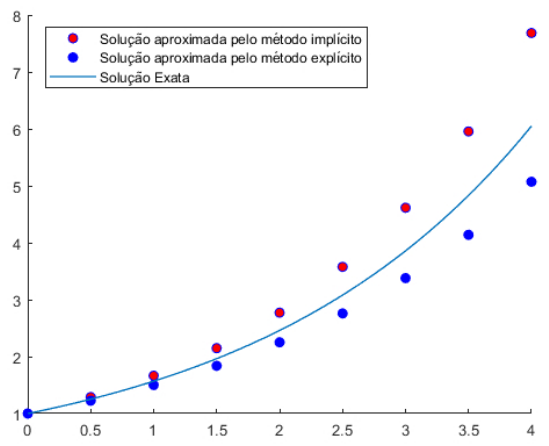

Tabela 1: Aproximações numéricas via (EE) e (EI) com dados (8).

Figura 4: Soluções exata e numérica (Euler explícito e implícito) para (9) com dados (8).

Intuitivamente, quanto menor h, melhor a aproximação numérica para o PVI. Implementamos então em Matlab o desenvolvimento da Figura 5 , onde agora ligaremos os pontos $\left(t_{i}, y_{i}\right)$ a $\left(t_{i+1}, y_{i+1}\right)$, $\mathrm{i}=1, \cdots, \mathrm{n}-1$, por segmentos de reta.

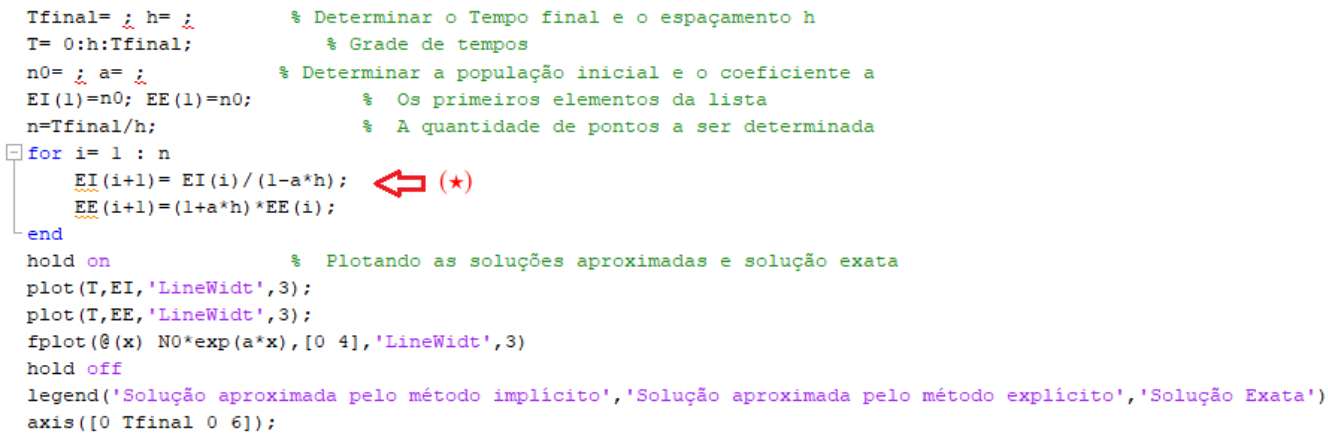

Figura 5: Algoritmo geral para (EE) e (EI) para o problema (6). Precisamos determinar $\mathrm{T}_{\text {final }}$, h, n0 e a := b-d, . 
Apresentamos nas figuras 6 e 7 alguns exemplos abaixo com alguns outros valores.

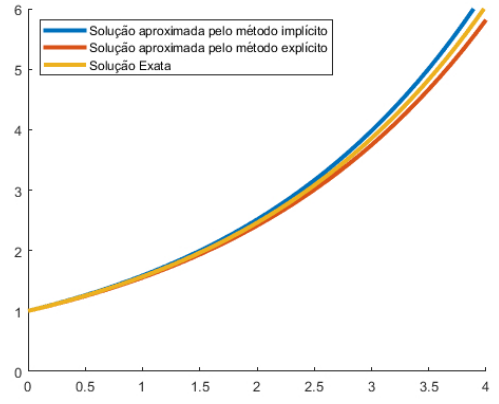

Figura 6: Aplicação do Algoritmo da Figura 5 com $\mathrm{T}_{\text {final }}=4, \mathrm{~h}=0.1, \mathrm{n} 0=1$ e $\mathrm{a}=0.45$.

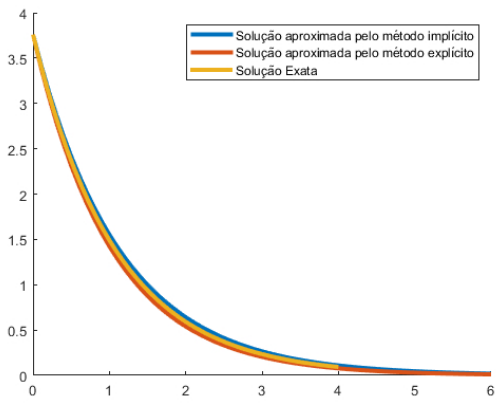

Figura 7: Aplicação do Algoritmo da Figura 5 com $\mathrm{T}_{\text {final }}=6, \mathrm{~h}=0.1, \mathrm{n} 0=3.76$ e a $=$ -0.925 .

Voltando ao problema populacional, podemos observar que essa abordagem não corresponde à realidade e sugere que modelos mais realistas devam ser propostos. No entanto, um clássico exemplo é considerar as estimativas de crescimento passadas e previstas para a população mundial total do século XVII ao século XXI, que mostram que tal abordagem não é tão ruim e pode ser adequada para o início da dinâmica, como podemos ver nas figuras 8 e 9, que mostram tais dados para as populações americanas e francesas num período catalogado.

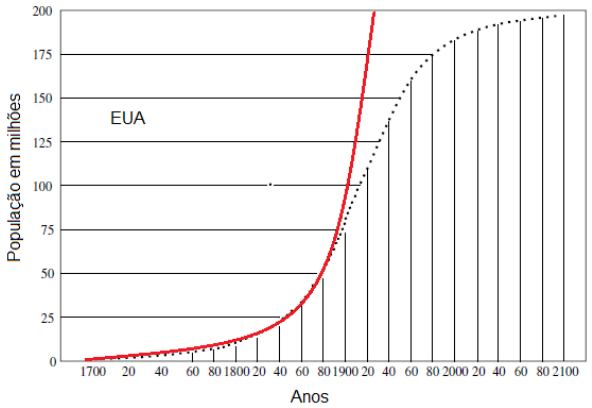

Figura 8: Crescimento populacional do EUA ao longo de alguns anos e previsões futuras (Figura adaptada de [11])

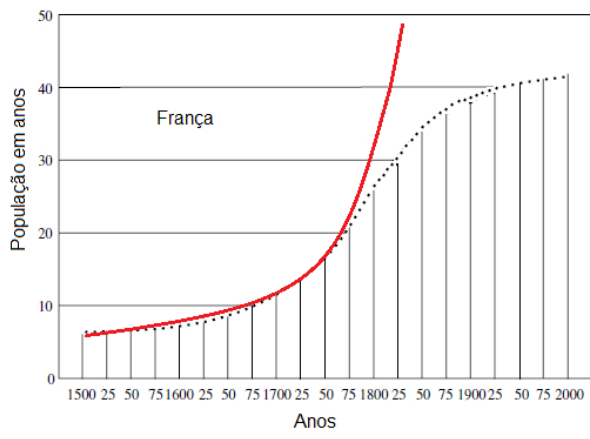

Figura 9: Crescimento populacional da França ao longo de alguns anos e previsões futuras (Figura adaptada de [11])

O modelo (6) e a teoria da transição demográfica de Warren Thompson (1887-1973) ajudam-nos a entender os modelos populacionais mais sofisticados. Thompson, em sua teoria, observou as mudanças que tinham experimentado nos últimos duzentos anos as sociedades industrializadas do seu tempo com respeito às taxas de natalidade e de mortalidade. De acordo com essas observações, expôs os quatro estágios da teoria da transição demográfica pelos quais a sociedade pós-industrial passa:

- Processo que acontece antes da industrialização, a fase 1 é caracterizada com elevadas taxas de natalidade compensadas por altas taxas de mortalidade. Muitas crianças morreram antes de 
atingir a idade adulta, e as doenças e fomes foram generalizadas. A expectativa de vida era menor do que hoje, mas, em média, mais crianças nasceram para cada mãe. Nessa época não existiam métodos contraceptivos e as condições de saúde eram precárias;

- A melhoria nas condições sanitárias, a evolução da medicina e a urbanização aumentam a expectativa de vida na fase 2 , onde os índices de mortalidade iniciam importante descida. Surgem problemas como a explosão demográfica, superpopulação e aumento do desemprego;

- Na fase 3 ocorre um declínio na taxa de natalidade devido ao acesso a métodos anticoncepcionais, o elevado custo de vida nas grandes metrópoles e o acesso à educação, fazendo com que o planejamento familiar fique mais difundido;

- Na fase 4 as taxas de natalidade e mortalidade encontram-se muito baixas, e é criada uma estabilização no crescimento vegetativo, tendo por consequência uma taxa de crescimento natural nula ou negativa.

Atualmente se fala em uma quinta fase, onde a mortalidade superará a natalidade, devido ao alto custo de se criar filhos (principalmente em países desenvolvidos) e famílias optam por ter um número muito reduzido (entre 1 e nenhum) de filhos para manter o padrão de vida. Alemanha e Itália são exemplos de países nessa fase, onde se cria a preocupação quanto ao rombo que isso pode acarretar na previdência.

As figuras 8 e 9 mostram os resultados colhidos para a população dos EUA e da França entre 1790 e 1910, junto à previsão para os próximos anos, segundo modelos mais realistas. Há um bom ajuste para a população no período catalogado, que representas as fases 1 e 2 da teoria de Thompson. No entanto, o resto da curva solução de (5) não está nem perto dos dados reais da população, uma vez que na fase 3 há a redução do número de nascimentos. O ponto principal não é que as previsões sejam tão imprecisas usando (5), mas sim que a curva ajuste apenas parte dos dados, e particularmente a parte que não cobre a maior parte da curva de crescimento torne a comparação com dados e previsões futuras extremamente não confiáveis. Grosso modo, um modelo mais realista que a abordagem feita em (5) seria dizer que a variação da população $\mathrm{N}$ tem crescimento exponencial caso essa população seja pequena (fases 1 e 2), que essa desacelera a partir de uma certa quantidade de indivíduos (fase 3) e que há mortalidade quando a população $\mathrm{N}$ for muito grande (fase 4). Visando isso, a longo prazo, deve haver algum ajuste a esse crescimento exponencial e uma proposta que se adequa seria

$$
\left\{\begin{array}{l}
\frac{\mathrm{d}}{\mathrm{dt}} \mathrm{N}=\mathrm{rN}(1-\mathrm{N} / \mathrm{K}) \quad \Rightarrow \mathrm{N}(\mathrm{t})=\frac{\mathrm{n}_{0} \mathrm{Ke}^{\mathrm{rt}}}{\mathrm{K}+\mathrm{n}_{0}\left(\mathrm{e}^{\mathrm{rt}}-1\right)}, \\
\mathrm{N}(0)=\mathrm{n}_{0},
\end{array}\right.
$$

onde $\mathrm{r}$ e $\mathrm{K}$ são constantes positivas. É interessante observar que $\mathrm{N}(\mathrm{t}) \stackrel{\mathrm{t} \rightarrow+\infty}{\rightarrow} \mathrm{K}$. Esse modelo é conhecido por crescimento logístico em uma população. Neste modelo, a taxa de natalidade per capita é $\mathrm{r}(1-\mathrm{N} / \mathrm{K})$, isto é, depende de $\mathrm{N}$. Essa taxa de crescimento indica que, conforme a densidade populacional $\mathrm{N}$ aproxima-se de $\mathrm{K}$ a taxa de crescimento vai se aproximando de zero e estabilizando. Assim, a constante K num contexto geral é a capacidade de carga do ambiente, que geralmente é determinada pelos recursos de sustentação disponíveis.

Trabalhando da mesma forma como feito em (6), temos as abordagens por Euler-explícito dadas 
por

$$
\frac{d}{d t} N=r N(1-N / K) \Rightarrow \frac{N_{i+1}-N_{i}}{h}=r_{i}\left(1-N_{i} / K\right) \Rightarrow\left\{\begin{array}{l}
N_{i+1}=N_{i}+h r N_{i}\left(1-N_{i} / K\right), \\
i=1, \cdots, n-1, \\
N_{1}=n_{0},
\end{array}\right.
$$

e para Euler-implícito, temos

$$
\begin{aligned}
\frac{\mathrm{d}}{\mathrm{dt}} \mathrm{N}=\mathrm{rN}(1-\mathrm{N} / \mathrm{K}) \quad & \Rightarrow \frac{\mathrm{N}_{\mathrm{i}+1}-\mathrm{N}_{\mathrm{i}}}{\mathrm{h}}=\mathrm{rN}_{\mathrm{i}+1}\left(1-\mathrm{N}_{\mathrm{i}+1} / \mathrm{K}\right) \\
& \Rightarrow \quad\left\{\begin{array}{l}
\mathrm{N}_{\mathrm{i}+1}-\mathrm{N}_{\mathrm{i}}-\mathrm{rhN}_{\mathrm{i}+1}\left(1-\mathrm{N}_{\mathrm{i}+1} / \mathrm{K}\right)=0, \\
\mathrm{i}=1, \cdots, \mathrm{n}-1, \\
\mathrm{~N}_{1}=\mathrm{n}_{0} .
\end{array}\right.
\end{aligned}
$$

Notemos que agora o problema (EI) não é totalmente trivial. Em cada passo, a fim de determinar quem é o valor $\mathrm{N}_{\mathrm{i}+1}$, precisamos obter o zero de uma função apropriada, isto é, para cada $\mathrm{i}=$ $1, \cdots, \mathrm{n}-1$,

$$
\mathrm{N}_{\mathrm{i}+1}-\mathrm{N}_{\mathrm{i}}-\operatorname{rhN}_{\mathrm{i}+1}\left(1-\mathrm{N}_{\mathrm{i}+1} / \mathrm{K}\right)=0 \quad \Rightarrow \quad \mathrm{F}\left(\mathrm{N}_{\mathrm{i}+1}\right)=0, \operatorname{com} \mathrm{F}(\mathrm{x})=\mathrm{x}-\mathrm{N}_{\mathrm{i}}-\operatorname{rhx}(1-\mathrm{x} / \mathrm{K}),
$$

onde é preciso que se veja bem: em cada passo que queremos determinar $\mathrm{N}_{\mathrm{i}+1}$ já temos conhecido o valor $\mathrm{N}_{\mathrm{i}}$. Por exemplo, a fim de determinar $\mathrm{N}_{2}$, isto é,

$$
\mathrm{N}_{2}-\mathrm{N}_{1}-\operatorname{rhN}_{2}\left(1-\mathrm{N}_{2} / \mathrm{K}\right)=0 \stackrel{\mathrm{N}_{1}=\mathrm{n}_{0}}{\Rightarrow} \mathrm{F}\left(\mathrm{N}_{2}\right)=0, \quad \operatorname{com} \mathrm{F}(\mathrm{x})=\mathrm{x}-\mathrm{n}_{0}-\operatorname{rhx}(1-\mathrm{x} / \mathrm{K}) .
$$

Obtendo o zero de $\mathrm{F}$, temos o $\mathrm{N}_{2}$. De forma indutiva, para determinar o $\mathrm{N}_{3}$, temos

$$
\mathrm{N}_{3}-\mathrm{N}_{2}-\mathrm{rhN}_{3}\left(1-\mathrm{N}_{3} / \mathrm{K}\right)=0 \quad \text { Agora já conhecemos } \mathrm{N}_{2} \quad \mathrm{~F}\left(\mathrm{~N}_{3}\right)=0, \operatorname{com} \mathrm{F}(\mathrm{x})=\mathrm{x}-\mathrm{N}_{2}-\mathrm{rhx}(1-\mathrm{x} / \mathrm{K}) \text {, }
$$

e assim por diante. Claro que não é nenhum grande desafio obter os candidatos a $N_{i}, i=1, \cdots, n-1$, já que em cada passo acima, para determinar o zero de cada $\mathrm{F}$ podemos simplesmente usar a fórmula de Bhaskara. A fim, porém, de se dar mais complexidade ao modelo, eventualmente, surgirá a necessidade de obter zeros de função em geral de forma eficiente.

Zeros de funções: Dos métodos clássicos para aproximar zeros de funções vamos usar bissecção (intervalar) e o método de Newton-Raphson (método de ponto fixo), porém, os desenvolvimentos podem ser estendidos para os demais casos. Da teoria elementar, de forma bastante resumida, temos os métodos intervalares sendo, em geral, convergentes, porém lentos. Enquanto isso, os métodos de ponto fixo são mais eficientes, desde que o pontapé inicial esteja próximo da solução. Os métodos intervalares, em geral, são bem empregados para iniciarmos algum método de ponto fixo, e é essa técnica que iremos utilizar. Todos esses métodos citados podem ser vistos em [4], por exemplo.

Para fixar as ideias, usaremos primeiramente o método da bissecção e consideramos o problema (10) com dados

$$
\mathrm{n}_{0}=0.36, \quad \mathrm{r}=1.925, \quad \mathrm{~K}=3, \quad \mathrm{~T}_{\text {final }}=4, \quad \mathrm{~h}=0.25,
$$


isto é, aproximaremos numericamente a solução de

$$
\left\{\begin{array}{l}
\frac{\mathrm{d}}{\mathrm{dt}} \mathrm{N}=1.925 \mathrm{~N}(1-\mathrm{N} / 3) \\
\mathrm{N}(0)=0.36
\end{array} \quad \Rightarrow \quad \mathrm{N}(\mathrm{t})=\frac{0.36 \times 3 \mathrm{e}^{1.925 \mathrm{t}}}{3+0.36\left(\mathrm{e}^{1.925 \mathrm{t}}-1\right)}=\right.\text { Solução exata, }
$$

Apresentamos o algoritmo do método da bissecção como na Figura 10, com o esclarecimento de cada entrada apresentada na legenda.

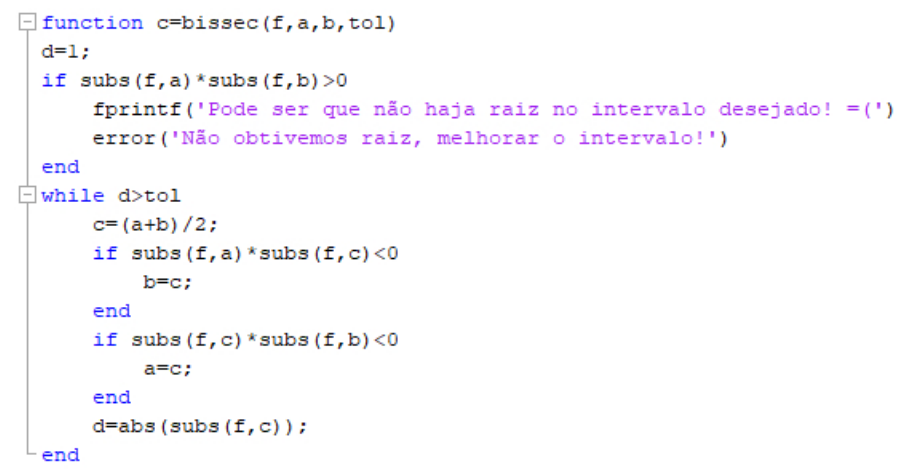

Figura 10: Algoritmo da Função Bisseç̧̃̃o: tem como entrada a função f que queremos determinar o zero, o intervalo $[\mathrm{a}, \mathrm{b}]$ onde acreditamos estar um zero de $\mathrm{f}$ e tol é a tolerância desejada.

Temos $\mathrm{N}_{1}=\mathrm{n} 0=0.36$, e obtemos $\mathrm{N}_{2}$ via $\mathrm{F}_{2}\left(\mathrm{~N}_{2}\right)=0, \operatorname{com~}_{2}(\mathrm{x})=\mathrm{x}-0.36-(0.25)(1.925) \mathrm{x}(1-\mathrm{x} / 3)$ :

$$
\mathrm{N}_{2}=\operatorname{bissec}\left(\mathrm{F}_{2}, 0.36-0.4,0.36+0.4,0.001\right) \quad \Rightarrow \quad \mathrm{N}_{2}=0.5885 \text {. }
$$

Temos $\mathrm{N}_{2}=0.5885$ e obtemos $\mathrm{N}_{3}$ via $\mathrm{F}_{3}\left(\mathrm{~N}_{3}\right)=0 \operatorname{com} \mathrm{F}_{3}(\mathrm{x})=\mathrm{x}-0.5885-(0.25)(1.925) \mathrm{x}(1-\mathrm{x} / 3)$ :

$$
\mathrm{N}_{3}=\operatorname{bissec}\left(\mathrm{F}_{3}, 0.5885-0.4,0.5885+0.4,0.001\right) \quad \Rightarrow \quad \mathrm{N}_{3}=0.8903 \text {. }
$$

Temos $\mathrm{N}_{3}=0.8903$ e obtemos $\mathrm{N}_{4}$ via $\mathrm{F}_{4}\left(\mathrm{~N}_{4}\right)=0 \operatorname{com} \mathrm{F}_{4}(\mathrm{x})=\mathrm{x}-0.8903-(0.25)(1.925) \mathrm{x}(1-\mathrm{x} / 3)$ :

$$
\mathrm{N}_{4}=\operatorname{bissec}\left(\mathrm{F}_{4}, 0.8903-0.4,0.8903+0.4,0.001\right) \quad \Rightarrow \quad \mathrm{N}_{4}=1.2404 \text {. }
$$

E assim sucessivamente. Temos os resultados para $\mathrm{N}_{\mathrm{i}}, \mathrm{i}=1, \cdots, 16$ apresentados na Tabela 2 na coluna referente a Euler-implícito (EI). Para obter a coluna referente ao método de Euler-explícito (EE) basta seguir o algoritmo com os dados (8).

No exemplo acima vimos uma forma bastante simples de obter os pontos referentes ao método de Euler-implícito (EI) utilizando o método da bissecção, e essa forma pode ser resumida em dois pontos abordados na Figura 12:

1 O método de Euler-implícito consiste em obter o zero de uma função; então, em cada passo precisamos calcular o zero de uma função adequada, ou seja, a f é atualizada em cada passo, como podemos ver em (13), (14) e (15).

2 O método da bissecção pede um intervalo [a,b] onde haja uma raiz da função f. Como esperamos que em cada passo o ponto obtido esteja razoavelmente próximo ao anterior, a fim de obter 
$\mathrm{EI}(\mathrm{i}+1)$ fizemos a proposta de que, como esse é a raiz de uma f adequada, EI $(\mathrm{i}+1)$ deve estar no intervalo [EI(i) - 0.4, EI(i) + 0.4]. Dependendo do crescimento/decrescimento da solução, a proposta de um intervalo centrado em EI(i) de raio 0.4 pode não ser um intervalo adequado, precisando de um ajuste para cima. Da mesma forma, considerando h pequeno, esse intervalo pode ser diminuído.

\begin{tabular}{|c|c|c|}
\hline $\mathbf{t}$ & EE & EI \\
\hline \hline 0 & 0.3600 & 0.3600 \\
\hline 0.25 & 0.5125 & 0.5885 \\
\hline 0.5 & 0.7170 & 0.8903 \\
\hline 0.75 & 0.9795 & 1.2404 \\
\hline 1.0 & 1.2970 & 1.5993 \\
\hline 1.25 & 1.6513 & 1.9303 \\
\hline 1.5 & 2.0086 & 2.2101 \\
\hline 1.75 & 2.3280 & 2.4313 \\
\hline 2.0 & 2.5790 & 2.5983 \\
\hline 2.25 & 2.7532 & 2.7199 \\
\hline 2.5 & 2.8622 & 2.8063 \\
\hline 2.75 & 2.9255 & 2.8678 \\
\hline 3.0 & 2.9604 & 2.9103 \\
\hline 3.25 & 2.9792 & 2.9396 \\
\hline 3.5 & 2.9892 & 2.9586 \\
\hline 3.75 & 2.9944 & 2.9718 \\
\hline 4.0 & 2.9971 & 2.9806 \\
\hline
\end{tabular}

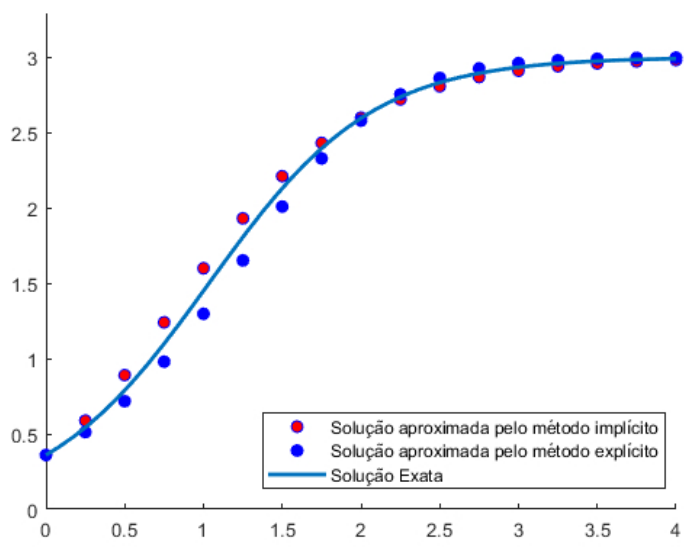

Figura 11: Soluções exata e numérica (Euler explícito e implícito) para (12) com $\mathrm{h}=0.25$

$\operatorname{EI}(i+1)=b i \operatorname{ssec}(F, E I(i)-0.5, \operatorname{EI}(i)+0.5,0.001)$;

Tabela 2: Aproximações numéricas via (EE) e (EI) utilizando a bissecção com dados (11).
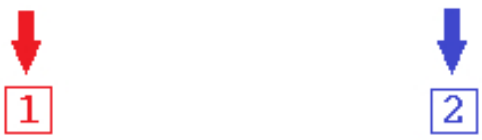

Figura 12: Construção do algoritmo.

Com essa discussão em mente, atualizamos o laço do algoritmo da Figura 5, como apresentado na Figura 13. Assim, podemos tomar h menor para obter melhor precisão.
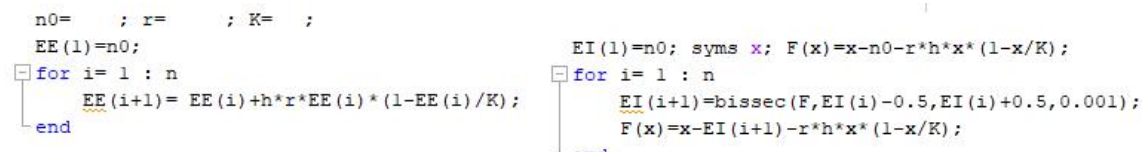

Figura 13: À esquerda temos (EE) e à direita a atualização do algoritmo do método de Euler-implícito (EI). Precisamos determinar $\mathrm{n} 0, \mathrm{r}$ e $\mathrm{K}$, além de mantermos a grade de tempo relativas a $\mathrm{h}$ e $\mathrm{T}_{\text {final }}$ apresentadas na Figura 5. Note que na Figura 5 tem-se que (*) é o passo em que precisamos determinar o zero de uma função.

Em vez de tomarmos h pequeno nesse algoritmo, vamos considerar o fato de que esse, de reprente, ficou lento. Como lembrado anteriormente, o método de bissecção é lento, e é geralmente usado para iniciarmos outros métodos, como por exemplo, o método de Newton-Raphson, onde a teoria elementar diz que se nosso pontapé inicial for suficientemente próximo do zero da função, 


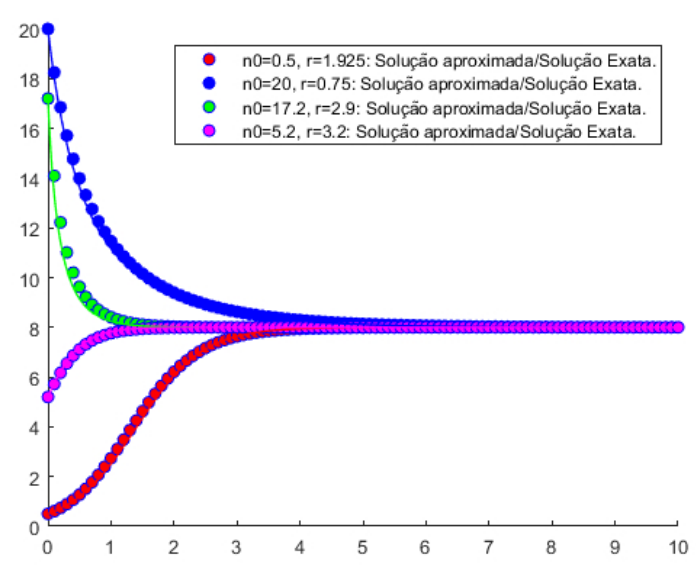

Figura 17: Soluções exatas/numéricas pelo método de Euler-implícito para $\mathrm{K}=10$ e $\mathrm{h}=0.1$ no intervalo de tempo $[0,10]$ para alguns valores de $\mathrm{r}$ e n0.

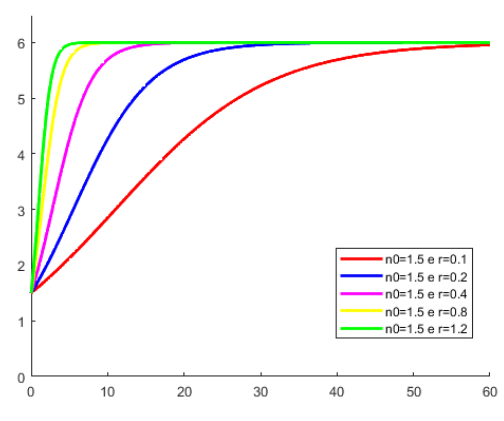

Figura 18: Soluções numéricas pelo método de Euler-implícito para $\mathrm{K}=8$ e $\mathrm{h}=0.1$ no intervalo de tempo $[0,60]$ para valores de $\mathrm{r}=$ $0.1,0.2,0.4,0.8,1.2$ e n0 = 1.5.

A teoria da transição demográfica junto com modelos matemáticos eficientes ajudam a descrever a sequência pela qual as sociedades são transformadas. Não há nenhuma contradição entre o fato de a taxa de natalidade decair e o fato de a população crescer, mesmo que em um ritmo menos acelerado. Isso ocorre porque, devido ao aumento da contracepção as taxas de natalidade devem cair, porém, devido aos efeitos de uma população jovem, o crescimento ainda deve acontecer por mais algumas décadas. Há uma considerável preocupação com as consequências do crescimento da população humana para o meio ambiente e para o desenvolvimento social e econômico. É concluído em [9] que esse crescimento provavelmente chegará ao fim em um futuro previsível, mostrando que há cerca de $85 \%$ de chance de que a população mundial pare de crescer antes do final do século e que existe a probabilidade de $60 \%$ de que a população mundial não exceda 10 bilhões de pessoas antes de 2100 , e cerca de $15 \%$ de probabilidade de que a população mundial no final do século seja menor do que 6 bilhões. Para diferentes regiões, a data e o tamanho da população de pico variam consideravelmente. Dados que chamam mais a atenção estão voltados para a região da China, onde a probabilidade de atingir um pico nas próximas duas décadas ainda é baixa devido à sua estrutura etária relativamente jovem, e na África Subsaariana, onde apesar da prevalência do HIV, há uma baixa probabilidade de atingir um pico antes da metade do século. A probabilidade chega a $25 \%$ em $2070,50 \%$ em 2085 e quase $75 \%$ em 2100 , devido a supostas reduções na fertilidade.

Estudos mais recentes (2019, Organização das Nações Unidas) mostram que, num contexto geral, desde 1900 a população mundial vem crescendo exponencialmente. Estima-se que, no início da década de 50, o número de pessoas no planeta era de aproximadamente 2,6 bilhões de pessoas. Seguindo o crescimento, a população mundial chegou em 5 bilhões de habitantes em julho de 1987, e 6 bilhões em outubro de 1999. Já em 2010 esse número já estaria em aproximadamente 7 bilhões de pessoas. Para o futuro, a projeção é que no ano de 2030 ter-se-iam 8,5 bilhões de pessoas no planeta. Fazendo análises sucessivas, para o ano de 2050 são previstos 9,7 bilhões de habitantes e, por fim, no ano de 2100 serão 11,2 bilhões de pessoas. Assim como toda projeção, tem-se um certo grau de incerteza quanto a concretização de tais fatos. Os dados acima citados são baseados em uma projeção média variante, ou seja, existem alguns fatores que podem vir a influenciar nesses valores. Alguns deles são, por exemplo, a taxa de fertilidade, onde projeta-se que a quantidade de 
filhos por mulher passe de 2,5 em 2019 para 2,2 em 2050; a expectativa de vida, onde espera-se que passe de 72,6 anos em 2019 para 77,1 anos em 2050; e as taxas de migração que, ainda não tão significante como os dois anteriormente citados, também pode gerar uma mudança no número populacional do planeta.

$\mathrm{O}$ crescimento exacerbado vem causando sérias consequências à população do planeta. Cada vez mais faltam recursos à saúde, ocorrem migrações de refugiados para países próximos, acelera-se a urbanização, aumenta a demanda por habitações, e ocorre a precariedade no abastecimento de água potável e alimentos, assim como a falta de saneamento básico, entre outros. Ainda em [9], também é feita uma análise semelhante, onde ressalta que na ausência de uma crise de mortalidade catastrófica, um aumento adicional na população mundial de 7 bilhões para quase 9 bilhões é inevitável, o que sugere que políticas apropriadas devam ser adotadas e programas implementados a fim de acelerar a transição demográfica. Além dos benefícios ambientais de uma transição acelerada para a estabilização da população na Ásia e na África, grandes benefícios de saúde, sociais e econômicos seriam alcançados. O número de mulheres que morrem no parto seria cortado, e a saúde e a educação das crianças melhorariam. A proporção de adultos para crianças dependentes aumentaria, criando oportunidade de investir mais na agricultura e na indústria. A promoção da contracepção e legitimação de famílias menores precisa ser uma das principais prioridades nessa região.

Durante a maior parte da história da humanidade, a população mundial cresceu de forma lenta dado o fato de os coeficientes de mortalidade serem muito elevados. Tais coeficientes foram, sobretudo, influenciados pelo frequente surgimento de epidemias e pandemias, que acometeram grandes parcelas da população, além de guerras que dizimaram milhões de pessoas, como é o caso das duas grandes guerras que ocorreram durante o Século XX. Alguns estudos (ver [14], por exemplo) apontaram que, geralmente, essas epidemias e pandemias foram ocasionadas em sua maioria por precariedade de higiene pessoal e saneamento básico, falta de conhecimentos médicos e baixos padrões de condições de vida. Assim, com uma grande baixa da população mundial, seja por doenças ou por guerras, o crescimento da mesma, que seguia um ritmo exponencial, pode ter um declínio considerável. Nos dias de hoje, as grandes epidemias e pandemias tornaram-se fatos de interesse mundial frente a situação de epidemia de Coronavírus (Covid-19), oficialmente declarada como pandemia em Março de 2020. O que muitos não sabem, no entanto, é que desde a antiguidade tem sido relativamente comum se ter registros desses eventos. Podem-se citar grandes epidemias e pandemias que foram surgindo durante toda a história e que influenciaram no decréscimo da população, tais como a Peste Negra (1346-1353) que assolou a Europa Medieval, matando entre 20 e 25 milhões de pessoas, o que era equivalente a $25 \%$ da população europeia na época; a "Gripe Espanhola" (1918-1920), que foi considerada uma das pandemias mais mortais já constatadas, sendo que cerca de 3\% a 5\% da população mundial foi morta pelo vírus gripal da H1N1 (ver [6]); a epidemia do Ebola (2007 e 2013-2016), que ocorreu sobretudo nos países da África, sendo um vírus altamente infeccioso e que pode acabar matando mais de $90 \%$ das pessoas que a contraem ${ }^{1}$, e, atualmente, o Covid-19 (também chamado de Coronavírus) preocupa a população mundial por ser um vírus de fácil transmissão e que tem, cada dia mais, mortes contabilizadas por sua conta.

Então, como proposto em (3) e (4), o modelo (10) requer tal ajuste, e comum na literatura (ver

\footnotetext{
${ }^{1}$ Ver https://www.msf.org.br/o-que-fazemos/atividades-medicas/ebola.
} 
$[11,1,12,5,2,8,10])$ é esses serem dados por

$$
\left\{\begin{array} { l } 
{ \frac { \mathrm { dN } } { \mathrm { dt } } = \mathrm { rN } ( 1 - \frac { \mathrm { N } } { \mathrm { K } } ) - \mathrm { P } ( 1 - \mathrm { e } ^ { - \frac { \mathrm { N } ^ { 2 } } { \mathrm { A } } } ) } \\
{ \mathrm { N } ( 0 ) = \mathrm { n } _ { 0 } , }
\end{array} \quad \left\{\begin{array}{l}
\frac{\mathrm{dN}}{\mathrm{dt}}=\mathrm{rN}\left(1-\frac{\mathrm{N}}{\mathrm{K}}\right)-\frac{\mathrm{BN}^{2}}{\mathrm{~A}^{2}+\mathrm{N}^{2}} \\
\mathrm{~N}(0)=\mathrm{n}_{0},
\end{array}\right.\right.
$$

onde estamos considerando em (3) e (4) o caso F $\equiv 1$. No caso de um efeito de predação acentuado, consideraremos $\mathrm{F}$ como nas figuras 1 e 2 .

Os métodos de Euler-explícito e Euler-implícito são bastante interessantes para fixar as ideias, porém não são de uso comum para resolver um problema de valor inicial com uma EDO, esse da forma

$$
\left\{\begin{array}{l}
\frac{\mathrm{dN}}{\mathrm{dt}}=\mathrm{f}(\mathrm{N}, \mathrm{t}) \\
\mathrm{N}(0)=\mathrm{n}_{0},
\end{array}\right.
$$

já que na literatura existem métodos mais acurados e que não têm problemas com erros acumulados. O estudo do método implícito, sobretudo, é interessante também para fixar as ideias tendo em vista que em problemas de ordem maior ou em problemas de valor inicial com uma EDP são predominantes os métodos implícitos, veja [4] para vários exemplos. Dentre os métodos que apresentam melhorias aos métodos implícito/explícito de Euler podemos citar o método de Heun, o método do ponto médio ou o método de Ralston, que são todos estendidos pelos métodos de Runge-Kutta:

A fim de aproximar numericamente a solução de (16) utilizaremos aqui o clássico método de Runge-Kutta de quarta ordem, que é o de uso mais comum no dia a dia, que, segundo [4], é dado por

$$
\mathrm{N}_{\mathrm{i}+1}=\mathrm{N}_{\mathrm{i}}+\frac{\mathrm{h}}{6}\left(\mathrm{~K}_{1}+2 \mathrm{~K}_{2}+2 \mathrm{~K}_{3}+\mathrm{K}_{4}\right)
$$

onde

$$
\begin{gathered}
\mathrm{K}_{1}=\mathrm{f}\left(\mathrm{t}_{\mathrm{i}}, \mathrm{N}_{\mathrm{i}}\right), \quad \mathrm{K}_{2}=\mathrm{f}\left(\mathrm{t}_{\mathrm{i}}+\frac{\mathrm{h}}{2}, \mathrm{~N}_{\mathrm{i}}+\frac{\mathrm{K}_{1} \mathrm{~h}}{2}\right), \\
\mathrm{K}_{3}=\mathrm{f}\left(\mathrm{t}_{\mathrm{i}}+\frac{\mathrm{h}}{2}, \mathrm{~N}_{\mathrm{i}}+\frac{\mathrm{K}_{2} \mathrm{~h}}{2}\right) \text { e } \mathrm{K}_{4}=\mathrm{f}\left(\mathrm{t}_{\mathrm{i}}+\mathrm{h}, \mathrm{N}_{\mathrm{i}}+\mathrm{K}_{3} \mathrm{~h}\right) .
\end{gathered}
$$

No que segue utilizaremos então o método para a análise numérica dos problemas de valores iniciais propostos, onde o algoritmo está destacado na Figura 19.

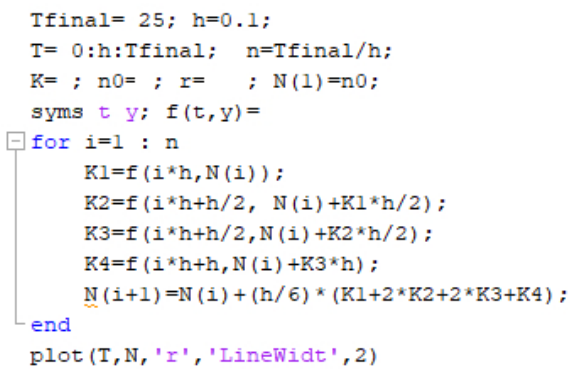

Figura 19: Algoritmo utilizado para Runge-Kutta de $4^{\underline{a}}$ ordem.

$$
\begin{aligned}
& \text { * Utilizaremos então para } \\
& \mathrm{f}(\mathrm{t}, \mathrm{y})=\mathrm{r} *(1-\mathrm{y} / \mathrm{K}) * \mathrm{y}-\mathrm{F}(\mathrm{t}) * \mathrm{P} *\left(1-\exp \left(-\mathrm{y}^{2} / \mathrm{A}\right)\right) \\
& \mathrm{e} \\
& \mathrm{f}(\mathrm{t}, \mathrm{y})=\mathrm{r} *(1-\mathrm{y} / \mathrm{K}) * \mathrm{y}-\mathrm{F}(\mathrm{t}) * \mathrm{P} * \mathrm{~N}^{2} /\left(\mathrm{A}^{2}+\mathrm{N}^{2}\right) \\
& \text { e testaremos alguns valores para } \mathrm{A} \text { e } \mathrm{P}_{0} \text { e } \mathrm{F}(\mathrm{t}) \\
& \text { conforme apresentadas nas figuras } 1 \text { e } 2 \text {. }
\end{aligned}
$$


Discutiremos numericamente nesse trabalho apenas o modelo (3), o modelo (4) segue de maneira similar. Consideremos então o problema de valor inicial

$$
\left\{\begin{array}{l}
\frac{\mathrm{dN}}{\mathrm{dt}}=\mathrm{rN}\left(1-\frac{\mathrm{N}}{\mathrm{K}}\right)-\mathrm{PF}(\mathrm{t})\left(1-\mathrm{e}^{-\frac{\mathrm{N}^{2}}{\mathrm{~A}}}\right) \\
\mathrm{N}(0)=\mathrm{n}_{0},
\end{array}\right.
$$

Num primeiro exemplo exibimos os resultados numéricos utilizando o método de Runge-Kutta considerando $F(t) \equiv 1$. Nas figuras 20 e 21 exibimos essa análise para alguns valores de A e $\mathrm{P}_{0}=\mathrm{P}$, onde consideramos para isso $\mathrm{K}=8, \mathrm{r}=1.1$ e $\mathrm{n} 0=1$.

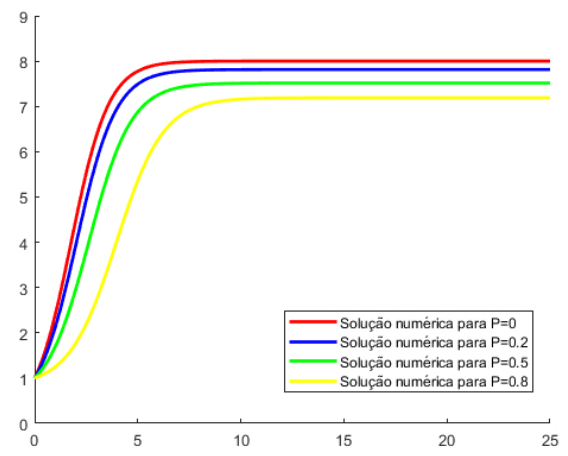

Figura 20: Solução numérica de (17) pelo método de Runge-Kutta de $4^{\underline{a}}$ ordem considerando $\mathrm{K}=8$, $\mathrm{r}=1.1, \mathrm{n} 0=1, \mathrm{~A}=0.1$ e $\mathrm{P}$ como na figura.

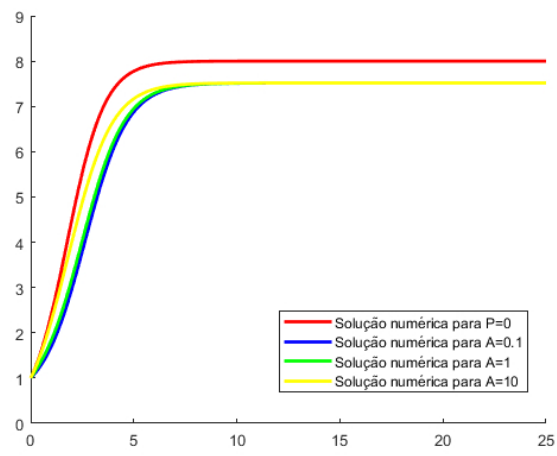

Figura 21: Solução numérica de (17) pelo método de Runge-Kutta de $4^{\underline{a}}$ ordem considerando $\mathrm{K}=8$, $\mathrm{r}=1.1, \mathrm{n} 0=1, \mathrm{P}=0.5$ e $\mathrm{A}$ como na figura.

Vale a pena observar que o resultado obtido com esse modelo ainda pode ser visto como um bom ajuste para dados como abordados nas figuras 8 e 9 para a população americana e população francesa ao longo dos últimos séculos. Como um exemplo ilustrativo, consideremos os dados colhidos e fornecidos por Statistisches Bundesamt (Federal Statistical Office of Germany) para a população alemã e pelo Istituto Nazionale di Statistica para a população italiana ao longo dos anos de 1900 a 2020. Exibimos nas figuras 22 e 23 os gráficos de ambas as populações ao longo desses anos. É possível ver os efeitos estudados influenciando na dinâmica populacional desses países nos períodos da Primeira Guerra Mundial (1914-1918) e Segunda Guerra Mundial (1939-1945).

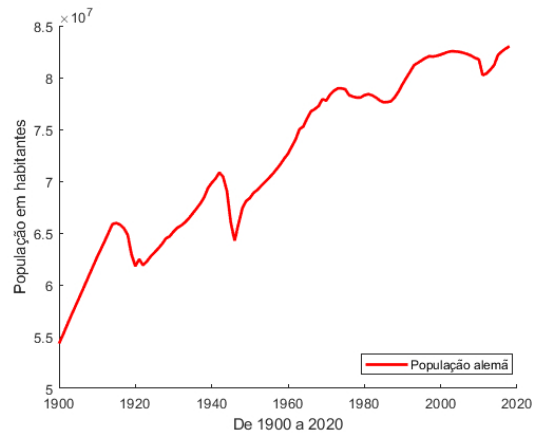

Figura 22: Gráfico da população alemã de 1900 a 2020.

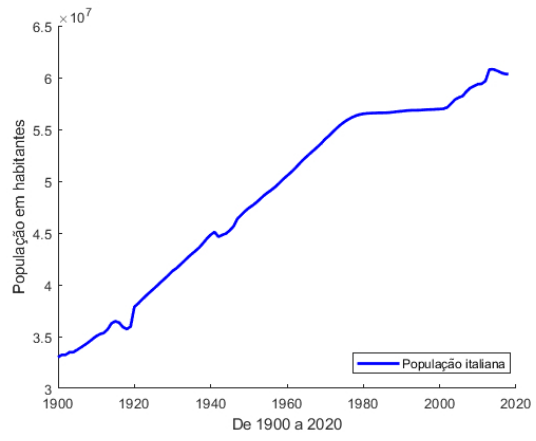

Figura 23: Gráfico da população italiana de 1900 a 2020. 
Talvez, isso fique mais claro se fizermos uma aproximação grosseira para um ajuste usando o modelo logístico (10), onde para Alemanha consideremos $\mathrm{r}=0.055$, n0 $=54.326 .000$ e $\mathrm{K}=80.500 .000$, e para a Itália consideremos $\mathrm{r}=0.047, \mathrm{n} 0=33.004 .000$ e $\mathrm{K}=57.000 .000$.

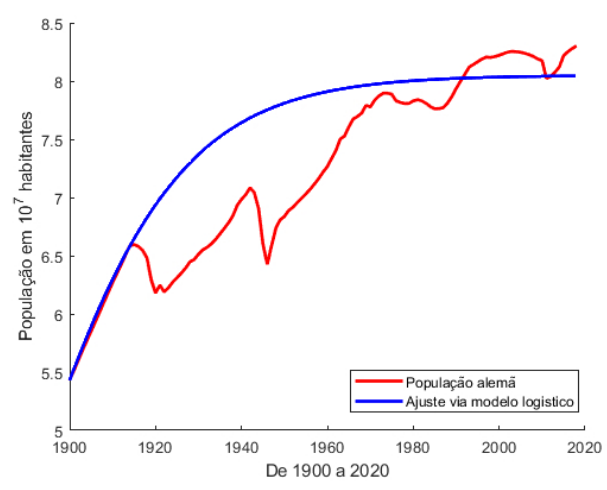

Figura 24: Ajuste ilustrativo para a população alemã com o modelo (10).

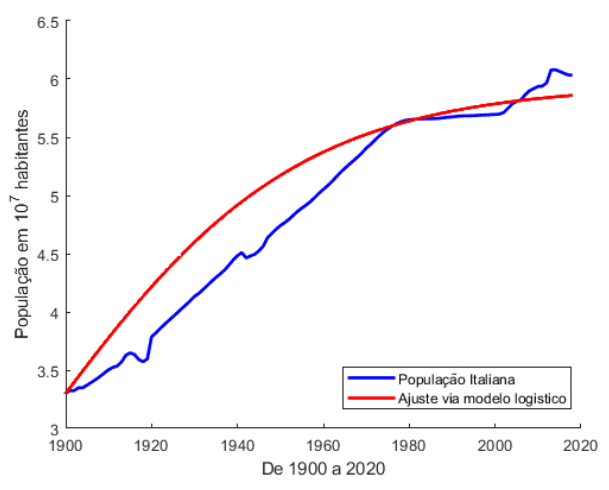

Figura 25: Ajuste ilustrativo para a população alemã com o modelo (10).

Provavelmente, essas análises ficariam ainda mais interessantes se considerássemos fatores de migração e imigração, que são muito comuns na história da Itália, por exemplo. A imigração italiana teve como ápice o período entre 1880 e 1930, enquanto que recebeu imigrantes devido às profundas mudanças econômicas e sociais induzidas pela industrialização do pós-guerra, incluindo baixas taxas de natalidade e envelhecimento da população. Consequentemente, com uma força de trabalho encolhida, durante os anos 80, a Itália passou a atrair fluxos crescentes de imigrantes estrangeiros. Podemos observar esses efeitos na Figura 25. Desde a queda do Muro de Berlim em 1989 e, mais recentemente, as ampliações da União Europeia em 2004 e 2007, as principais ondas de migração vieram dos antigos países da Europa Oriental, como Romênia, Albânia, Ucrânia e Polônia. O segundo fator mais importante de imigração para a Itália é ser vizinho ao norte da África, recebendo muitos imigrantes do Marrocos, Egito e Tunísia, por exemplo. Além disso, nos últimos anos, foram registrados fluxos crescentes de migração do Extremo Oriente, como China e Filipinas e também de países da América Latina, como Equador e Peru.

Então, a fim de ver os efeitos que esses impactos na taxa de predação podem fazer no crescimento populacional de uma comunidade, faremos então a abordagem considerando $\mathrm{F}$ da seguinte forma:

$$
\mathrm{F}(\mathrm{t})=1+\mathrm{ce}^{-\frac{(\mathrm{t}-\mathrm{t} 0)^{2}}{\mathrm{~d}}},
$$

com parâmetros $\mathrm{c} \in \mathbb{R}, \mathrm{d}>0$, onde já abordamos alguns exemplos nas figuras 1 e 2. Esperamos que com o efeito acentuado dado por $\mathrm{F}$ tendo ponto de máximo (c >0) haja retardo no crescimento da população ou até a reduza, e com ponto de mínimo (c < 0) aumente a população, como acontece quando há imigração, por exemplo. Lembramos que o parâmetro c representa a intensidade adicional que o termo de predação apresentará, e d podemos entender como o tempo em que esse efeito acentuado ocorre. No primeiro exemplo exibido na Figura 26 consideramos $\mathrm{F}(\mathrm{t})=7.2 \mathrm{e}^{-(\mathrm{t}-3.9)^{2} / 0.1}$. Observe que em azul está a solução com $\mathrm{F} \equiv 1$, donde podemos perceber que o efeito acentuado resultou num retardo no crescimento em certo período de tempo próximo a $t=3.9$ e com raio 0.1. Logo em seguida, na Figura 27, aumentamos o período de acentuação 
considerando $\mathrm{F}(\mathrm{t})=7.2 \mathrm{e}^{-(\mathrm{t}-3.9)^{2} / 0.8}$, e, na Figura 28, exibimos o resultado do aumento da intensidade para $\mathrm{F}(\mathrm{t})=11.6 \mathrm{e}^{-(\mathrm{t}-3.9)^{2} / 0.8}$. Em todos esses exemplos consideramos os mesmos parâmetros $\mathrm{r}=1.1$,

$$
\mathrm{K}=8, \quad \mathrm{n}_{0}=1, \quad \mathrm{~A}=0.1, \quad \mathrm{P}=0.2,
$$

No quarto experimento, exibido na Figura 29, consideramos também os dados (18), $\mathrm{r}=1.1$ e para a acentuação $\mathrm{F}$ consideramos $\mathrm{F}(\mathrm{t})=1+12 \mathrm{e}^{-(\mathrm{t}-0.4)^{2} / 0.001}+4 \mathrm{e}^{-(\mathrm{t}-4)^{2} / 0.4}+4 \mathrm{e}^{-(\mathrm{t}-10)^{2} / 2}$ onde indicamos que ao longo do tempo aconteceram três eventos que influenciaram diretamente no crescimento populacional. Nas figuras 30 e 31 exibimos os últimos dois experimentos com dados (18) e, no primeiro caso consideramos $\mathrm{r}=0.825$ e $\mathrm{F}(\mathrm{t})=1+12 \mathrm{e}^{-(\mathrm{t}-0.4)^{2} / 0.01}+8 \mathrm{e}^{-(\mathrm{t}-4)^{2} / 0.4}+4 \mathrm{e}^{-(\mathrm{t}-10)^{2} / 2}-$ $4.5 \mathrm{e}^{-(\mathrm{t}-25)^{2} / 15}$ e no segundo consideramos $\mathrm{r}=0.685$ e $\mathrm{F}(\mathrm{t})=1+\mathrm{e}^{-(\mathrm{t}-5)^{2} / 10}-2 \mathrm{e}^{-(\mathrm{t}-22)^{2} / 30}$, onde finalmente consideramos os efeitos de migração aumentando a população.

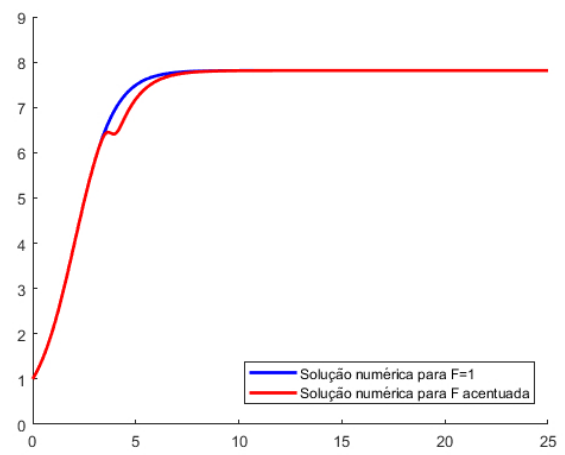

Figura 26: Solução numérica de (17) pelo método de Runge-Kutta de $4^{\underline{a}}$ ordem considerando (18), $\mathrm{r}=1.1$ $e \mathrm{~F}(\mathrm{t})=1+7.2 \mathrm{e}^{-(\mathrm{t}-3.9)^{2} / 0.1}$.

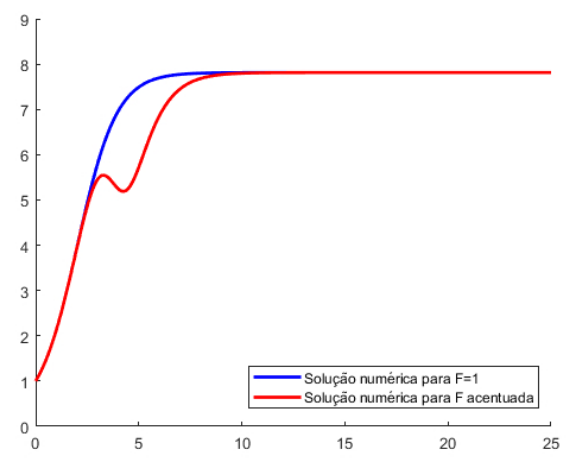

Figura 28: Solução numérica de (17) pelo método de Runge-Kutta de $4^{\underline{a}}$ ordem considerando (18), $\mathrm{r}=1.1$ $e \mathrm{~F}(\mathrm{t})=1+11.6 \mathrm{e}^{-(\mathrm{t}-3.9)^{2} / 0.8}$.

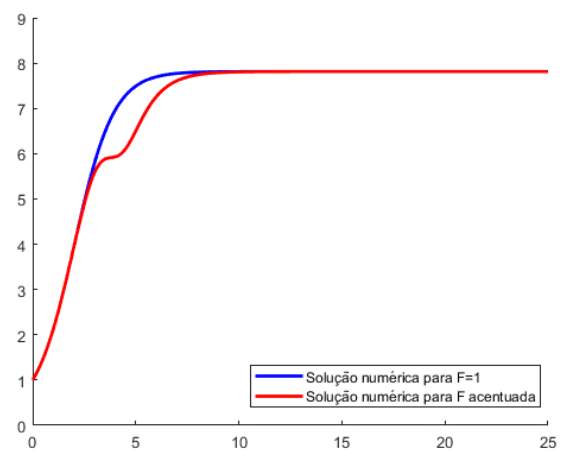

Figura 27: Solução numérica de (17) pelo método de Runge-Kutta de $4^{\underline{a}}$ ordem considerando (18), $\mathrm{r}=1.1$ $e \mathrm{~F}(\mathrm{t})=1+7.2 \mathrm{e}^{-(\mathrm{t}-3.9)^{2} / 0.8}$.

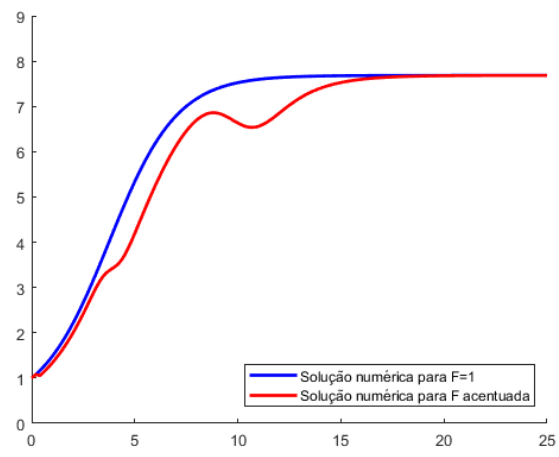

Figura 29: Solução numérica de (17) pelo método de Runge-Kutta de $4^{a}$ ordem considerando (18), $\mathrm{r}=$ 0.66 e $\mathrm{F}(\mathrm{t})=1+12 \mathrm{e}^{-(\mathrm{t}-0.4)^{2} / 0.001}+4 \mathrm{e}^{-(\mathrm{t}-4)^{2} / 0.4}+$ $4 \mathrm{e}^{-(\mathrm{t}-10)^{2} / 2}$. 


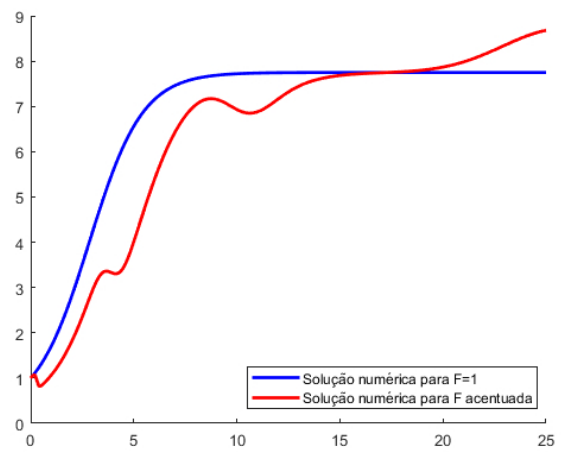

Figura 30: Solução numérica de (17) pelo método de Runge-Kutta de $4^{\underline{a}}$ ordem considerando (18), $\mathrm{r}=$ 0.825 e $\mathrm{F}(\mathrm{t})=1+12 \mathrm{e}^{-(\mathrm{t}-0.4)^{2} / 0.01}+8 \mathrm{e}^{-(\mathrm{t}-4)^{2} / 0.4}+$ $4 \mathrm{e}^{-(\mathrm{t}-10)^{2} / 2}-4.5 \mathrm{e}^{-(\mathrm{t}-25)^{2} / 15}$.

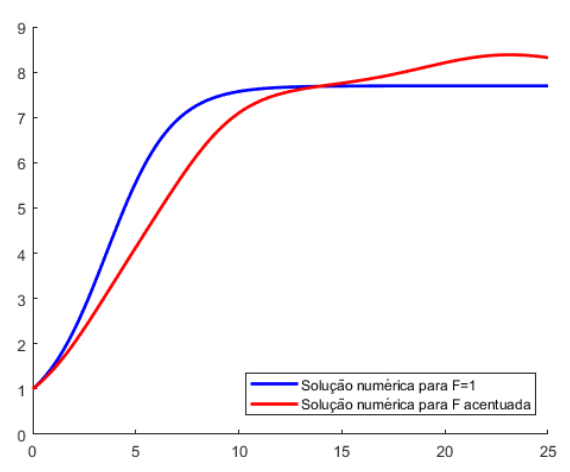

Figura 31: Solução numérica de (17) pelo método de Runge-Kutta de $4^{\underline{a}}$ ordem considerando (18), $\mathrm{r}=$ 0.685 e $\mathrm{F}(\mathrm{t})=1+\mathrm{e}^{-(\mathrm{t}-5)^{2} / 10}-2 \mathrm{e}^{-(\mathrm{t}-22)^{2} / 30}$.

Vale a pena observar que, apesar de conseguimos incluir tais efeitos no nosso modelo, essas técnicas não são de comum uso e é muito mais conveniente fazer uma aproximação do crescimento populacional de uma comunidade via o clássico modelo logístico (10). Assim, um ótimo exercício para concluir a atividade é fazer um ajuste como feito nas figuras 24 e 25 usando técnicas semelhantes a de quadrados mínimos com a solução exata apresentada à direita de (10), onde o objetivo seria encontrar obter os valores $\mathrm{K}$ e $\mathrm{r}$ adequados. O modelo logístico (10) foi introduzido em 1837 por Pierre F. Verhulst. Esse modelo foi comprovado como adequado para algumas espécies populacionais em modelos populacionais estáveis e experiências de laboratório. Citamos de [7] o exemplo do caso da população de focas no estado de Washington (EUA). No início do século passado, esses animais eram caçados por um programa do governo americano que via a espécie como um perigo, o que consequentemente reduziu o número de focas. Desde o fim do programa, a população de focas do estado de Washington recuperou-se seguindo um padrão aproximadamente logístico, sendo que o tamanho da população varia quando se atinge a capacidade de carga, com leves flutuações para cima e para baixo. Assim, vemos que apesar de seus problemas de limitações, ainda assim o uso desses métodos pode ser de grande utilidade para o desenvolvimento de teorias para a Ecologia.

\section{Referências}

[1] R. Angelini. Ecossistemas e modelagem ecológica. Perspectivas da Limnologia no Brasil, v. 1, pp1-19, 1999.

[2] A. Hastings, Population Biology - Concepts and Models, Springer 1996

[3] F.R.M. BARBOSA, M.P. CANALLI, "Qual a importância da relação professor-aluno no processo ensino-aprendizagem?"EFDeportes.com, Revista Digital. Buenos Aires, Ano 16, n. 160, 2011.

[4] L.R. Burden, J.D. Faires. Análise Numérica, $8^{\mathrm{a}}$ edição. [S.l.]: São Paulo, 2003.

[5] C. Cannings, F. Hoppensteadt, Mathematical methods of population biology. Cambridge University Press 1982

[6] J.N. Hays. Epidemics and pandemics. Their impacts on Human History. Austin, Texas: Fundação Kahle, 2005. 
[7] H. Huber, J. Laake. Trends and Status of Harbor Seals in Washington State: 1978-99. AFSC Quarterly Report, USA, pp1-13, 1 dez. 2002. (Archive)

[8] M. Kot, Elements of Mathematical Ecology, Cambridge University Press, 2001

[9] W. Lutz, W.C. Sanderson, S.Scherbov, The end of world population growth in the 21st century: new challenges for human capital formation and sustainable development. 1st Edition, 2004.

[10] P. Magal, S. Ruan, Structured Population Models in Biology and Epidemiology. Springer, 2008

[11] J.D. Murray, Mathematical Biology I - An Introduction. Third Edition, Springer, 2000.

[12] S.P. Otto, T.Day. A biologist's guide to mathematical modeling in ecology and evolution. New Jersey: Princeton University Press, 2007.

[13] E.M.S. SOARES,; L.Z. SAUER, "Um novo olhar sobre a aprendizagem de matemática para a engenharia". In: Cury, H.N. Disciplinas matemáticas em cursos superiores: reflexões, relatos, propostas. Porto Alegre: EDIPUCRS, 2004.

[14] J. Yunes. "A dinâmica populacional dos países desenvolvidos e subdesenvolvidos". Revista de Saúde Pública, [s.l.], v. 5, n. 1, pp129-150, jun. 1971. Fap-Unifesp (SciELO).

Bruno Telch dos Santos

Universidade do Estado de Santa Catarina <telchbruno@gmail.com>

Carolina Cominato

Universidade do Estado de Santa Catarina <cominatoc@gmail.com>

Rodrigo Cardoso dos Santos

Universidade Federal do Rio de Janeiro <rodrigo_cardoso_dos_santos@hotmail.com>

Recebido: 13/04/2020

Publicado: 17/07/2019 